\title{
Propuestas para una agenda en materia de derechos de propiedad rumbo al Bicentenario
}

\author{
Raúl Ravina***
}

Resumen. - El presente trabajo tiene como finalidad transmitir la importancia de la regulación de los derechos de propiedad en el Perú en los diferentes tipos de actividades por parte de personas naturales y jurídicas para el desarrollo de sus proyectos. En ese sentido, el lector podrá apreciar las principales críticas y oportunidades de mejora respecto a la regulación actual en nuestro país para lo cual se intentará detallar de forma didáctica y breve el "diagnóstico" de las principales instituciones para garantizar el acceso a los predios y cuál debiera ser su correcta interpretación en beneficio de la sociedad en general.

\begin{abstract}
The purpose of this work is to convey the importance of the regulation of property rights in Peru at different levels of activities by natural and legal persons for the development of their projects. In this respect, the reader will be able to appreciate the main criticisms and opportunities for improvement regarding the current regulation in our country; for this, we will try to briefly and didactically detail the "diagnosis" of the main institutions to guarantee access to the properties and what should be its correct interpretation for the benefit of society in general.
\end{abstract}

Palabras claves. - Derecho de Propiedad - Acceso a predios - Regulación - Propiedad Privada - Propiedad Estatal.

Keywords. - Property Law - Access to land - Regulation - Private Property - State Property.

* Socio del área de Derecho Inmobiliario y Construcción de CMS - Grau, es actualmente profesor de la Facultad de Derecho en la Universidad del Pacífico y ha sido profesor en la facultad de Derecho de la Pontifica Universidad Católica del Perú y la Universidad Peruana de Ciencias Aplicadas.

** Quiero agradecer muy especialmente a Luis Felipe Pajuelo y a Fernando Reyes Meléndez, por su colaboración en la elaboración de este artículo. 
"El poder supremo no puede apoderarse de parte alguna de la propiedad de un hombre, sin el consentimiento de éste; pues como el fin del gobierno es la preservación de la propiedad, y esa es la razón por la que los hombres entran en sociedad, ello implica necesariamente que al pueblo ha de permitírsele tener propiedades [...] Si bien tienen el poder de hacer leyes para regular la propiedad entre los súbditos, nunca pueden tener el poder de tomar para sí mismos, ni total ni parcialmente, la propiedad de los súbditos sin el consentimiento de éstos."

John Locke ${ }^{1}$

\section{Introducción}

El derecho de propiedad constituye una de las bases fundamentales para el desarrollo económico y social de una sociedad, pues determina las reglas de juego en relación a los bienes. Así, el derecho de propiedad regula a quién pertenece un bien, qué se puede y qué no se puede hacer con él y cómo se puede protegerlo.

Se ha escrito mucho en relación a la importancia del buen funcionamiento del marco institucional relativo al derecho de propiedad para promover el desarrollo económico. Autores como Ronald Coase, en su obra "El Problema del Costo Social", en el cual detalla las consecuencias de una determinada regulación del derecho de propiedad en las transacciones para maximizar o minimizar la productividad y sus costos; Guido Calabresi y Douglas Melamed quienes en su obra "Reglas de Propiedad, Reglas de Responsabilidad y de Inalienabilidad: Una Vista de la Catedral" determinan reglas de responsabilidad para la mejor asignación y valor del derecho de propiedad. Asimismo, Hernando De Soto, en su Obra "El Misterio del Capital" detalla las principales características que debe tener un ordenamiento legal para la distribución de los bienes y la regulación del derecho de propiedad dentro de un mercado global y un sistema capitalista.

Sin perjuicio de la importancia de la regulación del derecho de propiedad para facilitar el desarrollo económico, este sirve además como una herramienta de política social y promoción de las inversiones.

En ese sentido, el derecho de propiedad es parte de la infraestructura institucional con la que una sociedad cimienta su desarrollo, se relaciona con el estado y con el sector privado, con las familias del campo y de las ciudades, con la micro, mediana y gran empresa, con el agro, la industria, la infraestructura y el aprovechamiento de los recursos naturales. En general, los derechos de propiedad son claves tanto

1 LOCKE, Segundo Tratado sobre el Gobierno Civil, pp.172-173, y p. 174. 
para el desarrollo social como para el desarrollo empresarial y la economía en general.

El derecho de propiedad no supone sólo a la propiedad privada, existen diversos tipos de bienes que deben ser regulados de distintas maneras. al respecto Elinor

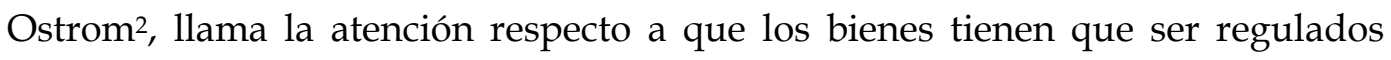
mediante un régimen de propiedad privada o de propiedad estatal y propone clasificar los bienes en razón de la facilidad para excluir a los demás en su aprovechamiento y de si el consumo es de rivalidad alta o baja, es decir si el consumo debe ser netamente individual o si se puede dar de forma colectiva. Como consecuencia de la aplicación de estos criterios, Ostrom rompe la vieja dicotomía entre bienes privados y bienes públicos e identifica a los denominados bienes comunes o bienes públicos impuros. Los bienes comunes comparten con los bienes públicos la condición de que la exclusión para su explotación es difícil, pero comparten con los bienes privados el hecho de la explotación es básicamente individual (rivalidad alta).

Tipología de los bienes

\begin{tabular}{|l|l|l|}
\hline & Rivalidad Baja & Rivalidad Alta \\
\hline $\begin{array}{l}\text { Exclusión } \\
\text { difícil }\end{array}$ & $\begin{array}{l}\text { Bienes públicos puros } \\
\text { Puestas de sol } \\
\text { Conocimientos acumulados }\end{array}$ & $\begin{array}{l}\text { Bienes públicos impuros o bienes } \\
\text { comunes } \\
\text { Bibliotecas } \\
\text { Sistemas de regadío }\end{array}$ \\
\hline $\begin{array}{l}\text { Exclusión } \\
\text { fácil }\end{array}$ & $\begin{array}{l}\text { Bienes privados impuros, } \\
\text { de club o de peaje } \\
\text { Televisión por cable } \\
\text { Guaderías infantiles }\end{array}$ & $\begin{array}{l}\text { Bienes privados puros } \\
\text { Ordenadores personales } \\
\text { Ropa y alimentación }\end{array}$ \\
\hline
\end{tabular}

Fuente: Elinor Ostrom (2006) adaptado por Alvaro Ramis (2013; p.118)

A partir de los criterios establecidos por Ostrom sugerimos el siguiente esquema para la distribución de los tipos de derecho de propiedad (privada, estatal y común o comunal) de acuerdo a criterios de exclusión y consumo.

2 RAMIS, A. El concepto de los bienes comunes en la obra de Elinor Ostrom. Revista Ecología Política, (45) 116-121, 2013. 


\begin{tabular}{|c|c|c|c|}
\hline \multirow{2}{*}{} & \multicolumn{3}{|c|}{ Exclusión } \\
\hline \multirow{2}{*}{} & & Posible & No posible \\
\cline { 2 - 4 } & Individual & Propiedad privada & $\begin{array}{c}\text { Propiedad comunal de } \\
\text { libre acceso/Propiedad } \\
\text { estatal con libre acceso }\end{array}$ \\
\cline { 2 - 4 } & Colectivo & $\begin{array}{c}\text { Propiedad privada/ } \\
\text { Propiedad estatal con } \\
\text { exclusiones }\end{array}$ & Propiedad estatal \\
\hline
\end{tabular}

Fuente: Elaboración propia ${ }^{3}$

En consecuencia, a efectos de regular adecuadamente los bienes escasos en la sociedad y recurriendo a las diversas características que estos pueden tener, se han generado tres tipos de derechos de propiedad; el derecho de propiedad privada, el derecho de propiedad estatal y el derecho propiedad común o comunal. Cada uno de ellos pone un énfasis distinto en la forma en que se ejercen los atributos de la propiedad $\mathrm{y}$, por lo tanto, tratan el problema de la escasez con formas $\mathrm{y}$ resultados diferentes ${ }^{4}$.

La propiedad privada supone que el titular del bien tiene un derecho exclusivo respecto al mismo y puede excluir al resto de la sociedad respecto de éste. En contraparte, el titular se hace responsable de los costos que involucre su bien. Al concentrar tanto los costos y los beneficios que genera el bien en su titular, se entiende que se generan los incentivos adecuados para la adecuada explotación y mantenimiento del bien.

Con la propiedad estatal es el Estado quien asume la titularidad del bien y quien debe determinar la forma en que este se explotará.

Finalmente, en la propiedad común el bien pertenece a un grupo determinado de personas que comparten los derechos y obligaciones relativos a este. La propiedad común o comunal se da normalmente al interior de grupos que comparten un espacio físico, una historia y una cultura. La Constitución de 1993 reconoce la existencia de estos tres tipos de derechos de propiedad, sin privilegiar uno respecto a otro. Esto es coherente en tanto, como hemos indicado, los tipos de derechos de propiedad tienen distinto contenido y deben responder a las características de los bienes y los objetivos que se quieren alcanzar.

3 En base al cuadro elaborado por ELINOR OSTROM (2006) adaptado por Alvaro Ramis (2013; p.118).

4 DEMSETZ, Harold, "Hacia una Teoría de los Derechos de Propiedad". Publicado en la American Economic Review en Mayo de 1967. 
La protección constitucional del derecho de propiedad incluye una serie de condiciones que buscan garantizar su debido ejercicio, entre las que se destacan:

- Se declara su inviolabilidad, salvo en casos de seguridad nacional o necesidad pública declarada por ley y previo pago de indemnización justipreciada (artículo $70^{\circ}$ ).

- $\quad$ Se establece que nacionales extranjeros (personas naturales o jurídicas) reciben el mismo trato en cuanto a sus derechos de propiedad, con excepción de los bienes inmuebles ubicados dentro de los cincuenta kilómetros de las fronteras (artículo $71^{\circ}$ ).

- Se restringen las restricciones y prohibiciones temporales para la adquisición, posesión, explotación y transferencia de determinados bienes a causas de seguridad nacional justipreciada (artículo $72^{\circ}$ ).

- $\quad$ Se establece que la los bienes de dominio público (propiedad estatal) son inalienables e imprescriptibles y que los bienes de uso público pueden ser cedidos a particulares conforme a ley, para su aprovechamiento económico (artículo $73^{\circ}$ ).

- $\quad$ En relación al agro, el Estado garantiza el derecho de propiedad sobre la tierra, en forma privada o comunal o en cualquier otra forma asociativa. También se establece que la ley puede establecer limites a la extensión de las tierras y que las tierras abandonadas, pasan a dominio del Estado para su adjudicación en venta (artículo 88 $8^{\circ}$.

- La propiedad comunal es imprescriptible, salvo en el caso de abandono (artículo 89).

Sin embargo, planteada la importancia y lo esencial de la regulación del derecho de propiedad, no basta con plasmar estos conceptos ideales en la constitución o en las leyes. Para que el derecho de propiedad logre facilitar el desarrollo, es necesario que su marco regulatorio e institucional brinde las condiciones adecuadas para su mejor funcionamiento.

En el Perú, el marco normativo e institucional relativo a los derechos de propiedad no cumple adecuadamente con este objetivo, lo que conlleva, entre otros problemas, a altos índices de informalidad y desorden entre los predios urbanos, rurales y eriazos del país.

En nuestra opinión, lo que falla en el Perú es la falta de una visión integral del manejo del derecho de propiedad y, a partir de ello, establecer un camino coherente que aborde sus diversos aspectos.

En esa línea, queremos plantear algunos temas que consideramos que deben ser abordados como parte de una agenda en materia de derechos de propiedad en el Perú. Adicionalmente, haremos referencia a el próximo cambio de gobierno y como podría impactar esto en relación a los derechos de propiedad. 


\section{El diagnóstico}

\section{i. Dispersión institucional y normativa}

En el Perú tenemos una amplia distribución de competencias en relación a los derechos de propiedad. Entidades como el Ministerio de Vivienda Saneamiento y Construcción (MVSC), Ministerio de Agricultura (MINAGRI), Ministerio de Justicia (MINJUS), Ministerio de Economía y Finanzas (MEF), Ministerio de Justicia, Ministerio de Transportes y Comunicaciones, Superintendencia Nacional de Registros Públicos (SUNARP), Superintendencia Nacional de Bienes Estatales (SBN), Organismos de Formalización de la Propiedad Informal (COFOPRI), Gobiernos Regionales, Municipalidades, entre otras, tienen atribuciones relevantes en materia de derechos de propiedad pero actúan de manera disgregada sesgando sus políticas de acuerdo a visiones fraccionadas. En el siguiente cuadro se puede apreciar la distribución de entidades involucradas en temas relacionados con derechos de propiedad en el país.

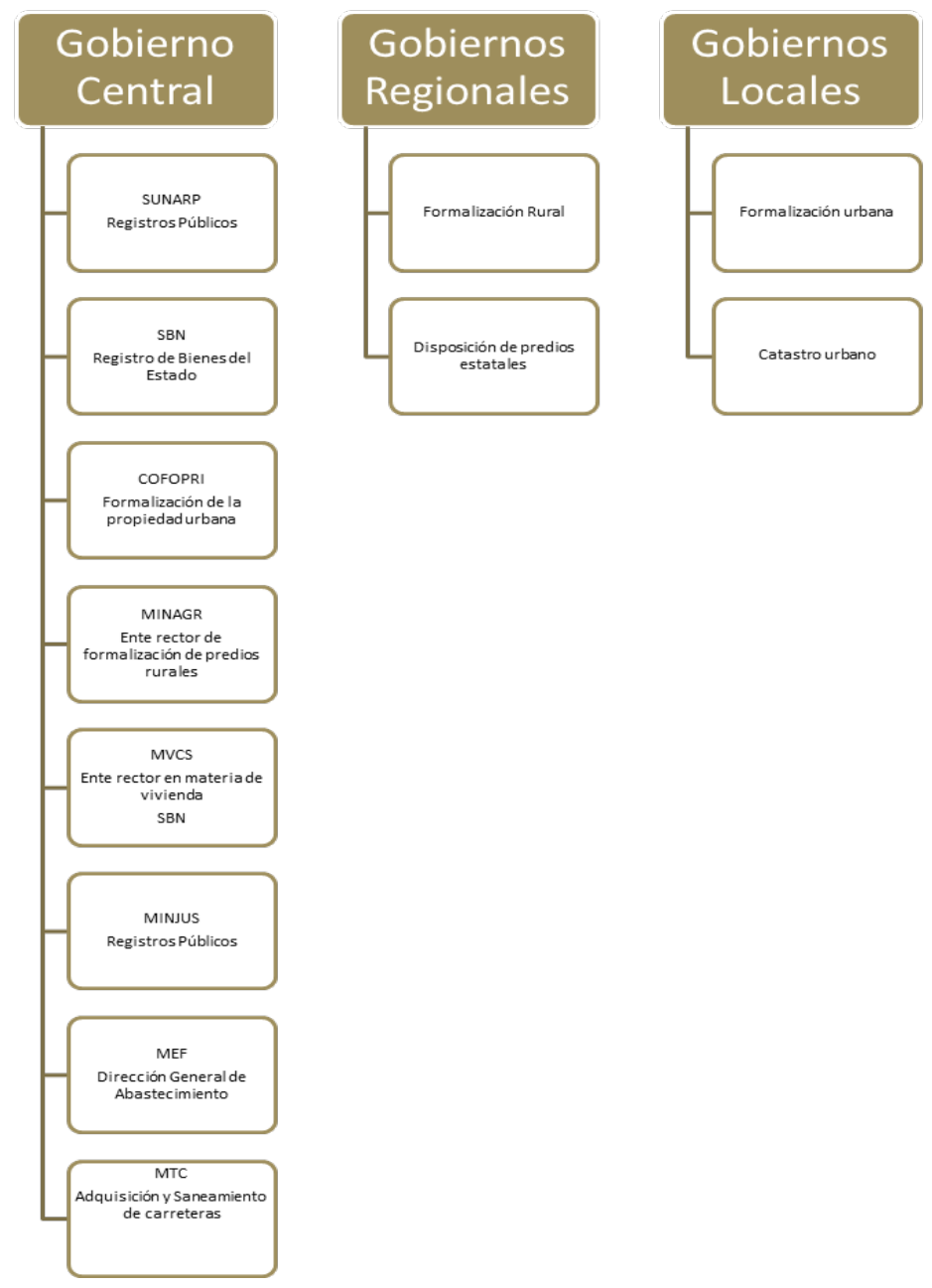

Fuente: Elaboración propia 
Se podría pensar que el desalineamiento institucional se da básicamente entre los distintos niveles institucionales (Gobierno Central, Gobiernos Regionales y Gobiernos locales), sin embargo, a nivel de las entidades del gobierno central existen visiones e intereses que no coinciden y que mucho menos priorizan los intereses de los ciudadanos y el desarrollo económico del país. En efecto, a nivel de las entidades que dependen del gobierno central se nota que, al formar parte de diferentes sectores, las entidades enfrentas los temas relativos a los derechos de propiedad con visiones distintas, lo que se traduce en problemas de coordinación que traban o alargan innecesariamente los procesos relacionados con los derechos de propiedad.

Por ejemplo, una entidad sectorial puede estar interesada en el desarrollo de un proyecto de inversión (infraestructura, minería, energía, etc) y busca que este proyecto tenga un acceso directo y rápido a las tierras estatales necesarias para su desarrollo, sin embargo, la entidad titular de estas tierras puede estar interesado en que esas tierras se utilicen para otra actividad, por la compensación económica que deben recibir a cambio de la tierra, en el mero mantenimiento de las tierras en su titularidad o simplemente puede ser un tema que no les genera interés para “acelerar" el proceso.

En otras ocasiones, más de una entidad se encuentra interesada en realizar cierta función y "compiten" por ver quien se hace cargo. Esto pasó hace unos años entre el PETT y COFOPRI, con respecto a qué ente debería liderar el proceso de formalización integrado a nivel urbano y rural. Esta suerte de "competencia" entre entidades no redunda en mayores eficiencias que favorecen a los usuarios, al contrario, se traduce en trabas y baja coordinación que terminan generando demoras y afectando los derechos de los ciudadanos.

Un ejemplo de esta dispersión institucional lo encontramos en relación al tema de los catastros. En el año 2004, se promulgó la Ley N²8294, que creó el Sistema Nacional Integrado de Catastro y su Vinculación con el Registro de Predios, entre los objetivos de este sistema se encuentran; regular la integración y unificación de los estándares, nomenclatura y procesos técnicos de las diferentes entidades generadoras de catastro en el país. El referido sistema está integrado por la Superintendencia Nacional de los Registros Públicos - SUNARP, los gobiernos regionales, las municipalidades provinciales, distritales, el Instituto Geográfico Nacional (IGN), el Instituto Nacional de Concesiones y Catastro Minero (INACC).

Sin embargo, dieciséis años después, no contamos aún con un sistema integrado de catastro, las entidades siguen manejando procesos técnicos dispares, los registros públicos no cuentan con un sistema de catastro que brinden seguridad jurídica y no existe un mecanismo integrado de acceso a la información predial que permita que los agentes económicos y el propio estado pueda acceder a información integrada para la toma de decisiones de inversión con relación a los predios. El motivo, cada una de estas entidades sigue operando de manera autónoma y desintegrada, sin manejar una sola visión estratégica y, en algunos 
casos, compitiendo entre ellas por el protagonismo y liderazgo al interior del sistema.

Un problema relacionado con la dispersión institucional se relaciona con el proceso de descentralización de facultades que se realizaron de entidades del gobierno central que tenían competencias nacionales y que se han disgregado a nivel de los gobiernos regionales y los gobiernos locales. Por ejemplo, COFOPRI, que en algún corto periodo concentró las funciones de formalización de la propiedad urbana y rural, perdió sus competencias en favor de los gobiernos regionales (formalización de la propiedad rural) y de los gobiernos locales (formalización de la propiedad urbana).

Otro problema que se presenta es que, al estar las competencias tan dispersas, el presupuesto y el personal calificado tiene que dividirse entre múltiples entidades. Por ejemplo, entidades como COFOPRI y la SBN carecen de personal suficiente para satisfacer en plazos razonables solicitudes de los usuarios. Lo mismo ocurre a nivel de regiones y municipios. Este problema se hace más agudo cuando hablamos del personal más calificado pues es muy escaso y termina siendo "completado" por funcionarios que carecen de la formación adecuada y de la visión necesaria. Esto se traduce en que la mejora regulatoria relativa a los procedimientos relacionados con los derechos de propiedad se encuentra básicamente detenida a pesar que aún se mantienen muchas trabas que afectan a los usuarios. Por ejemplo, el limitado acceso de los ciudadanos a información de las entidades (SBN, COFOPRI, RRPP, etc), las demoras en los procedimientos (Catastro rural, adjudicaciones, servidumbres, etc), la interpretación normativa se hace de la firma más restrictiva posible, por no incurrir en responsabilidad e incluso se emiten normas que restringen las propias competencias de las entidades. También podemos citar el caso del otorgamiento de derechos de servidumbre con fines de inversión en el sector eléctrico, en el que el Ministerio de Energía y Minas (MEM) se autoimpuso como requisito que el proyecto cuente con concesión definitiva, haciendo que en la práctica esta alternativa sea básicamente inútil ${ }^{5}$.

En consecuencia, sugerimos rediseñar el marco institucional relativo a los derechos de propiedad y contar con una instancia al más alto nivel que asuma las competencias disgregadas que puedan consolidarse y que concentre la función regulatoria en materia de derechos de propiedad.

En las siguientes paginas desarrollaremos otros problemas prácticos que nuestro sistema genera para los agentes económicos y el propio estado y expondremos como la falta de unidad de visión y criterios al interior del estado es muchas veces el origen de estos problemas.

5 En estos casos el acceso a la tierra se requiere inicialmente para realizar los estudios necesarios para obtener la concesión definitiva. Cuando ya se cuenta con la concesión definitiva, el concesionario puede acceder a una servidumbre sectorial que en muchos casos será gratuita a diferencia de los que sucede con la citada servidumbre que en todos los casos es onerosa. 


\section{ii. Informalidad}

Por diversas razones, la informalidad predial es un fenómeno extendido tanto en al ámbito urbano como el rural. Frente a ello, desde la década del noventa del siglo pasado se desarrollaron dos importantes programas masivos de titulación y formalización de la propiedad.

En el ámbito urbano, se creó la Comisión de Formalización de la Propiedad Informal $^{6}$ (COFOPRI) que tenía entre sus funciones desarrollar un programa destinado a lograr la titulación y formalización de la propiedad urbana en el Perú con el objetivo de brindar seguridad jurídica a las viviendas y facilitar la capitalización y el acceso al crédito de los peruanos. El programa de formalización desarrollado por COFOPRI se basó inicialmente en un proceso de mejora regulatoria y de procesos permanente, lo que permitió reducir los costos y los tiempos de titulación de 6 años a 45 días a un costo promedio de USD 68.00 contra los USD 3,500 en la Favela Barrio, en Río de Janeiro, Brazil7.

Posteriormente, COFOPRI perdió la competencia de formalización que fue transferida a los gobiernos locales. Sin embargo, COFOPRI se ha adaptado a esta realidad ofreciendo sus servicios como entidad técnica de apoyo de dichos gobiernos, adicionalmente, se reenfocó en el desarrollo de catastros urbanos a nivel nacional.

En el ámbito rural, se creo el Programa Especial de Titulación de Tierras (PETT) que se encargaba de la titulación de predios rurales y de comunidades a nivel nacional. En nuestra opinión, este proceso no se realizó siguiendo criterios técnicos sino más bien guiado por objetivos políticos que no necesariamente reditúan en el bienestar de los ciudadanos ${ }^{8}$.

En general, la formalización de la propiedad es una función que debe entenderse, al menos en su etapa masiva, como una función temporal y, como tal, es más eficiente implementar un programa a nivel nacional que cuente con el personal y equipos necesarios para esta labor. Luego, una vez concluida la etapa masiva, es más lógico descentralizar la ejecución de los procesos de formalización, dejando la parte regulatoria y de seguimiento y control en manos de un ente central, una suerte de superintendencia en materia de formalización de la propiedad, que de unidad y coherencia a la ejecución de estos procesos descentralizados.

Proponemos repensar la formalización de los derechos de propiedad de manera que se organicen considerando los siguientes elementos:

6 Hoy Organismo de Formalización de la Propiedad Informal.

7 CALDERÓN COCKBURN, Julio. Profesor de la Universidad Nacional de Ingeniería, Maestría FAUA POLÍTICA DE FORMALIZACIÓN. COMO INSTRUMENTO DE. INCLUSIÓN SOCIAL.https://www.sunarp.gob.pe/ECR/PPT-XIIcongresoNacionalexponentes/Julio\%20Calder\%C3\%B3n.pdf

8 Por ejemplo, de acuerdo con COFOPRI, el 61.5\% de las comunidades campesinas tituladas no se encuentran geo-referenciadas. Al respecto se puede consultar el informe de la Defensoría del Pueblo Nº02-2014-DP/AMAPPI-PPI. 
A. Enfocar la formalización de la propiedad como un proceso permanente de mejora regulatoria. En ese sentido, debe ponerse énfasis a la identificación y eliminación de costos de transacción para el acceso y el mantenimiento de los derechos de propiedad en la formalidad.

B. Debe entenderse que lo más importante en el tema formalización de la propiedad es el proceso de mejora regulatoria permanente y no las tareas específicas de formalización que pueden ser perfectamente descentralizadas e incluso tercerizadas. Durante los primeros años de trabajo de COFOPRI esta entidad promovió diversos cambios normativos y procedimentales dirigidos a romper con los "cuellos de botella" que complicaban el acceso a la propiedad formal, sin embargo, luego de esta etapa inicial, esta entidad dejó de ser un verdadero promotor de reformas, convirtiéndose más bien en una entidad ejecutora.

C. Entender las razones de la proliferación del acceso a la tierra tanto a nivel urbano como rural.

D. Promover reformas del marco normativo e institucional que ataque las causas que generan la proliferación del acceso informal a la tierra y que estén destinadas al mejor funcionamiento de los derechos de propiedad.

E. La formalización de la propiedad, entendida en su sentido más amplio, justifica un trabajo permanente pues incluye mucho más supuestos que el de las invasiones de tierras (urbanas y rurales). En ese sentido, más allá de generarse programas temporales de formalización (como fue el caso del PETT y COFOPRI) se requiere un arreglo institucional permanente y unificado en esta materia.

F. Al respecto, el congreso acaba de aprobar la nueva Ley de Saneamiento Físico legal y Formalización de Predios Rurales (pendiente de su promulgación por el Poder Ejecutivo) y la Ley $\mathrm{N}^{\circ} 31056$, que amplía los plazos de la titulación de terrenos ocupados por posesiones informales y dicta medidas para su formalización. En ambos casos, estás normas amplían los plazos de formalización de predios urbanos y rurales, sin atacar las causas por las que estas ocupaciones informales se vienen produciendo. Han habido varios pronunciamientos en contra de esta ampliación de los plazos (básicamente en lo que se trata de las posesiones informales urbanas) que por lo demás se vienen produciendo de manera reiterada desde las primeras normas que regularon la formalización de la propiedad. En nuestra opinión, la ampliación de estos plazos es la consecuencia de no atacar el problema en su origen y que, más allá de que en un futuro se volverán a repetir los mismos argumentos en su contra, en tanto no enfrentemos los problemas que originan la informalidad, nos vamos a ver en la obligación de optar nuevamente por una ampliación de plazos. En ese sentido, o trabajamos en 
la "vacuna"9 o siempre tendremos que aplicar la "medicina" de la formalización.

G. Incluir alternativas de formalización para todos los supuestos de informalidad existentes. Esto implica poner énfasis no sólo en el fenómeno de la ocupación ilegal (invasión urbana o rural) y atacar casos de informalidad parcial (donde no hay invasión, por ejemplo, en la habilitación urbana informal) y de informalidad sobrevenida (por ejemplo, problemas de actualización sucesoria y catastral, tugurización, etc).

H. Hacer un seguimiento permanente de las actuaciones de las diversas instancias del Estado buscando determinar los efectos que se generarían en relación a los derechos de propiedad.

I. Deben generarse alternativas efectivas para la formalización de toda clase de predio a nivel nacional. Esto implicaría:

a. Generar alternativas y mejorar el marco regulatorio referido a la formalización de la propiedad de predios estatales y comunales que involucran un gran porcentaje los predios del país y cuya formalización ha avanzado poco o adolece de defectos de titulación, catastro, etc.

b. Promover un procedimiento destinado a la formalización de predios rústicos sin uso agropecuario. Actualmente, la formalización de la propiedad no urbana se restringe a la formalización de predios con uso agropecuario, lo que planteamos es que se formalicen también los predios eriazos y aquellos dedicados a uso distintos (infraestructura pública, explotación de recursos naturales, etc).

\section{iii. Seguridad jurídica}

SUNARP, como cabeza del sistema registral, es una entidad que se relaciona estrechamente con todo el sistema de derechos de propiedad y cumple la importante función de generar oponibilidad y seguridad jurídica a los usuarios. La seguridad jurídica implica varias aristas que incluyen contar con funcionarios que actúen de acuerdo a ley y con un sistema de inscripción que garantice la invulnerabilidad de los derechos inscritos.

En cuanto al comportamiento de los funcionarios (registradores) creemos que es importante que su actuar sea previsible y que esté exento de arbitrariedades. Respecto a la previsibilidad, es importante fortalecer el trabajo de unificación de criterios que realizan los tribunales registrales, sin que eso signifique que se afecte la autonomía de los registradores. El otro elemento que creemos que se debe

9 Facilitar el acceso formal a la tierra. 
trabajar es la estandarización de los títulos que permitan una calificación simplificada y ágil con la finalidad de promover las inscripciones y se facilite el uso del registro, en especial para los segundos actos y el mantenimiento en la formalidad.

En esa línea con la finalidad de involucrar a los Registros Públicos en la política de manejo integrado de los derechos de propiedad, proponemos:

A. Revisar los procedimientos de inscripción registral poniendo énfasis en la simplificación, estandarización y automatización de los procesos. Para ello debe tenerse en cuenta experiencias exitosas como las de los procesos de inscripción generados por el PETT y COFOPRI.

B. Establecer mecanismos que promuevan el uso del sistema registral por toda la población y así evitar la re-informalización de los derechos de propiedad.

C. Es necesario revisar los costos de los servicios que brinda registros públicos con la finalidad de hacerlos más accesibles a toda la población.

D. Mejorar el sistema catastral de las oficinas registrales con la finalidad de otorgar mayor seguridad jurídica a los derechos inscritos en el registro. Esta es una tarea urgente que creemos que debería abordarse teniendo en cuenta los siguientes criterios:

a. La falta de un catastro que se vincule con cada una de las partidas registrales genera en la práctica inseguridad en todo el sistema.

b. En su oportunidad, el Registro Predial Urbano generó un sistema que relacionaba las partidas registrales con su catastro. Esto debe extenderse a todos los predios inscritos a nivel nacional.

c. La implementación de un sistema de catastro que se relacione con las partidas registrales dará lugar a la identificación de diversos problemas de desplazamiento físico, superposiciones y falta de antecedentes que debería ser abordado. En ese sentido, debería generarse un procedimiento administrativo que permita resolver estos problemas de manera masiva para aquellos casos en que no se presente la oposición de terceros.

d. Debe generarse un mecanismo administrativo para la inmatriculación de predios de manera análoga a lo que se realiza en los procedimientos de formalización. La idea es evitar los casos en que se debe acudir al poder judicial (proceso de título posesorio) en los casos que no exista oposición de terceros. 


\section{iv. Falta de visión pro cuidadano}

En nuestra opinión, este es uno de los problemas transversales que están presentes en las distintas entidades que tienen competencias vinculadas con los derechos de propiedad. Por ejemplo, en entidades como la SBN, COFOPRI y en los Registros Públicos, entidades estrechamente ligadas al acceso al derecho de propiedad, nos encontramos con funcionarios que tienen pocos incentivos para acceder a las solitudes de los usuarios y tienden a denegarlas para evitar incurrir en algún tipo de responsabilidad.

En esa misma línea, se modifican algunos procedimientos, tanto formalmente como en la práctica, con la finalidad de "proteger" a los funcionarios agregando pasos y plazos a procedimientos que podrían ser mucho más simples, siempre en desmedro de los intereses de los ciudadanos.

Luego tenemos los temas vinculados a los costos de los servicios, en algunos casos, a pesar que las tasas administrativas deben limitarse a cubrir el costo efectivo del servicio prestado por la entidad, tenemos casos en que esto no se cumple. Por ejemplo, en el caso de SUNARP, las tasas registrales se establecen no en razón del costo del servicio sino del monto de la operación.

Otro ejemplo de la falta de enfoque en el ciudadano es el relacionado con la visación de planos en el ámbito rural. Este es un procedimiento necesario para acumular o subdividir predios, así como para presentar planos en procesos judiciales y está a cargo de los gobiernos regionales. A pesar de tratarse de un servicio que es fundamental para que la realidad de los predios pueda concordar con la información catastral y registral y para proteger el derecho de los usuarios ante el Poder Judicial, los gobiernos regionales ponen poco interés en atender estos servicios, en especial por temas de falta de personal y presupuesto. Como consecuencia, muchas solicitudes llegan a estar años sin ser atendidas, cuando no se llegan a extraviar los expedientes.

En ese sentido, proponemos iniciar un proceso intenso de mejora regulatoria y simplificación administrativa que ponga el foco en que los ciudadanos puedan acceder de manera expeditiva y económica al derecho de propiedad y a la seguridad jurídica, algunas reformas que se pueden plantear son:

A. Más allá de que se logre concentrar las competencias relacionadas con los derechos de propiedad en un sistema con una dirección común, es necesario hacer una revisión del funcionamiento real de los procedimientos más relevantes para los ciudadanos con la finalidad de identificar las oportunidades de mejora regulatoria y simplificación.

B. Alinear los incentivos de los funcionarios con los intereses de los usuarios, para ello se debe hacer una revisión de los procedimientos simplificándolos y reduciendo la discrecionalidad. Además, se debe evaluar la contratación de un seguro que proteja a los funcionarios que, actuando de acuerdo al 
marco normativo, generen un daño que deba ser resarcido, esto por supuesto no cubriría lo actos realizados de forma dolosa.

C. Establecer un control permanente de los cambios normativos y fácticos de los procedimientos que se vayan generando, con la finalidad de evitar que estos afecten los intereses ciudadanos y que los requisitos sean proporcionales y justificados.

D. Identificar los casos de tasas administrativas que exceden los costos reales del servicio y ajustarlas a este criterio.

E. Identificar los procedimientos que vienen realizándose en plazos excesivos y evaluar la forma de corregir esos excesos.

\section{v. Falta de visión pro inversión}

El otro problema transversal que está presente en el tratamiento de los temas relativos al derecho de propiedad es que no existe una política consistente que facilite el acceso a las tierras necesarias para el desarrollo de las inversiones que tienen como un componente necesario el acceso a predios. Proyectos de infraestructura, agroindustria, energía, minería, y otros, requieren el acceso a importantes extensiones de predios privados y estatales para su desarrollo.

Contradictoriamente, existen múltiples mecanismos regulados para facilitar el acceso a tierras para el desarrollo de proyectos de inversión. En el siguiente cuadro pueden apreciarse los procedimientos más destacados. 

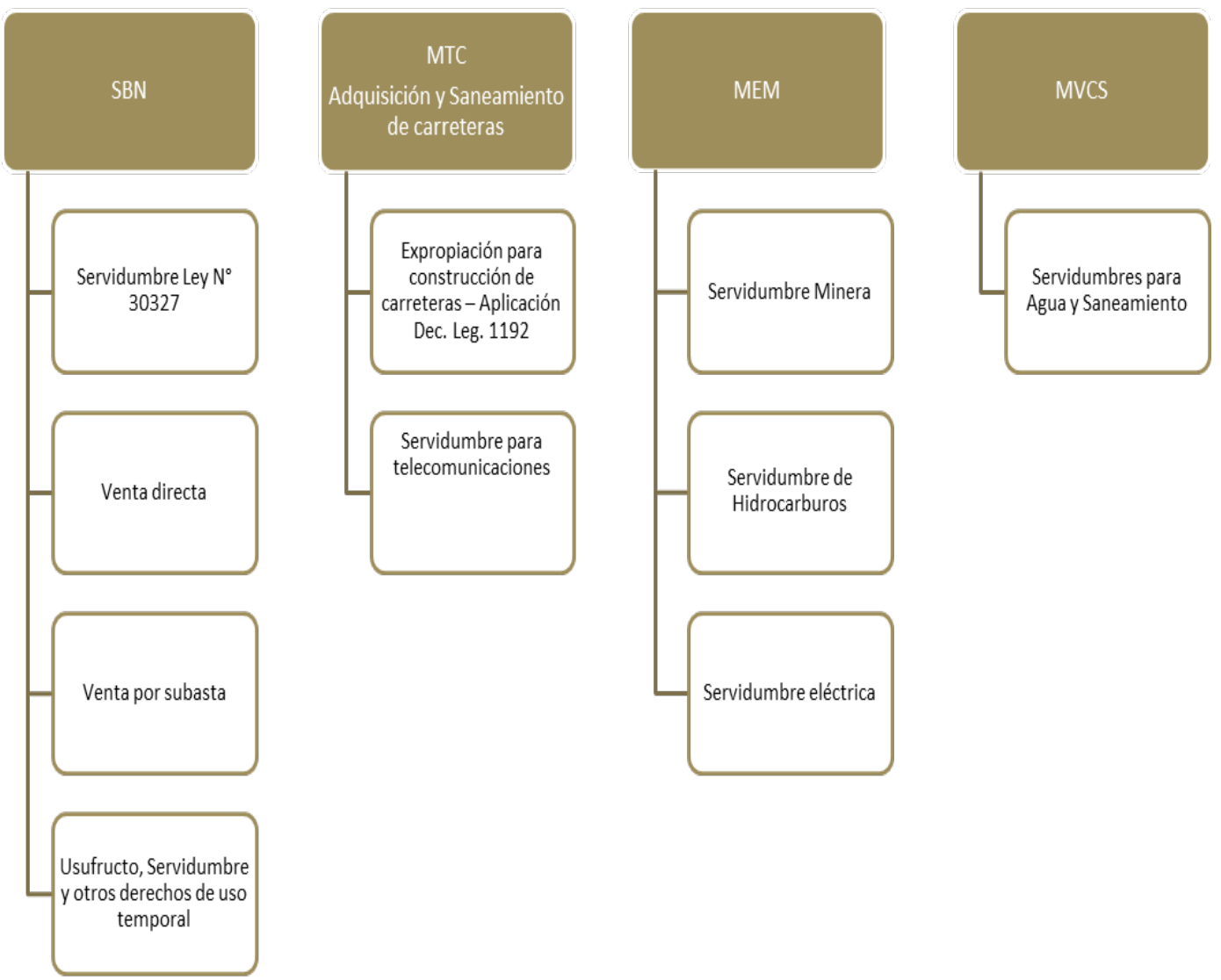

\section{Fuente: Elaboración propia}

A pesar de la gran variedad de alternativas existentes para que los proyectos de inversión obtengan los derechos prediales necesarios para su desarrollo, en la práctica la aplicación de estos procedimientos se hace lenta producto de decisiones y trámites que en muchos casos exceden o trastocan los procedimientos reglados.

Por ejemplo, en el año 2012 al interior de la SBN se decidió que, dado que el mercado predial empujaba los precios de los inmuebles al alza, no era conveniente vender inmuebles estatales pues era más conveniente otorgar derechos de uso temporal para después, una vez valorizados los predios, venderlos ${ }^{10}$. Esta lectura, más propia de un inversionista inmobiliario que de una entidad pública interesada en la promoción de la inversión, generó que durante mucho tiempo se suspendieron las ventas de inmuebles, lo que truncó el desarrollo de gran número de proyectos de inversión que se detuvieron o simplemente se dejaron de lado. Cabe agregar que, a esa fecha la compraventa de inmuebles estatales era el procedimiento más importante que manejaba la SBN para ceder predios para el desarrollo de proyectos privados y que la cesión temporal de derechos sobre

10 Ver entrevista a Sonia Cordero ex Superintendente de la SBN en el diario Gestión del 17/09/2012. Cabe comentar, que esa tendencia alcista en los precios de los inmuebles se detuvo y que es bien cuestionable si ese fenómeno se daba respecto a los predios que eran solicitados ante la SBN y no era más propio de zonas urbanas consolidadas y de expansión agroindustrial. 
inmuebles casi no se usaba11. Finalmente, cabe comentar que posteriormente la SBN hizo muy poco para hacer más accesible el otorgamiento de derechos de uso temporal para el desarrollo de proyectos, en consecuencia, lo único que se hizo fue postergar y frustrar diversos proyectos de inversión que hubiesen generado empleo, impuestos y demás beneficios para la sociedad.

De los problemas para el acceso a tierras para el desarrollo no se escapa ni el propio estado. En efecto, cuándo se requiere adquirir un predio privado para el desarrollo de algún proyecto estatal o concesionado al sector privado, se aplicará el Decreto Legislativo $\mathrm{N}^{\circ} 1192^{12}$ para realizar una adquisición convencional o forzosa (vía expropiatoria). A pesar de las diversas mejoras que esta norma trajo a la adquisición de predios por parte del estado (posibilidad de adquisición directa, bono especial por pronta entrega, mecanismos de saneamiento, ejecución coactiva, liberación de interferencias), la ejecución de estos procesos sigue siendo engorrosa. En nuestra opinión, esto es así básicamente por los problemas de interacción y de acceso a la información de las diversas entidades que participan en el proceso que, como hemos señalado anteriormente, dependen de sectores distintos, con prioridades muy diferentes.

$\mathrm{Al}$ respecto, hemos hecho una breve revisión de los tiempos normados del proceso normado en el Decreto Legislativo $N^{\circ} 1192$ y lo hemos comparado con los tiempos aplicables a los procedimientos que se siguen en los otros países que conforman la denominada Alianza del Pacifico ${ }^{13}$. Como se puede apreciar, el procedimiento regulado en el Perú es en general más largo que el aplicable en los otros países miembros ${ }^{1415}$ :

11 En sus modalidades de arrendamiento, usufructo, superficie, servidumbre y cesión en uso.

12 Ley Marco de Adquisición y Expropiación de inmuebles, transferencia de inmuebles de propiedad del Estado, promulgada el 23 de agosto de 2015, a la fecha ha sido modificada en cuatro (04) ocasiones directamente a través de los Decretos Legislativos $\mathrm{N}^{\circ} 1210,1330,1366$ y 1486. Actualmente, todas las modificaciones se organizan y detallan en el Texto Único Ordenado aprobado por Decreto Supremo Nº15-2020-VIVIENDA promulgado el 26 de octubre de 2020.

13 Conformado por México, Colombia, Chile y Perú.

14 Esto puede variar si el proceso se judicializa, en el Perú esto se produce básicamente para cuestionar el monto indemnizatorio y se puede realizar tanto en la vía arbitral como judicial. En cualquier caso, previa consignación del monto estimado por el estado, este podrá avanzar con la liberación del predio mientras se discute en la vía arbitral o judicial.

15 Cuadros de elaboración propia. Para ello hemos contado con la colaboración de las áreas de derecho inmobiliario de las oficinas de CMS en México, Colombia y Chile. 


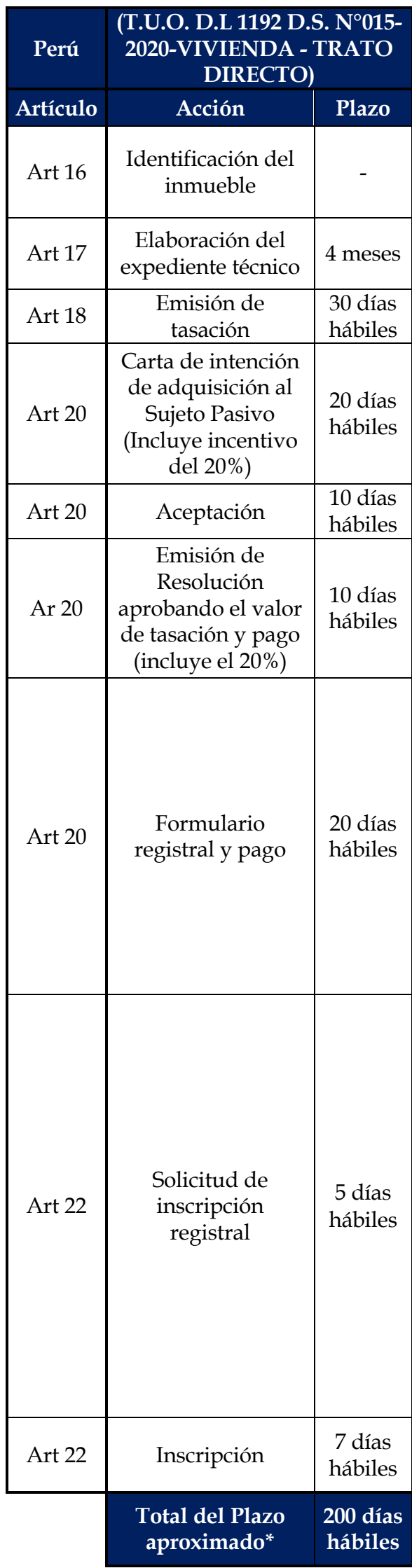

\begin{tabular}{|c|c|c|}
\hline Perú & \multicolumn{2}{|c|}{$\begin{array}{l}\text { (T.U.O. del D.L } 1192 \text { - D.S. Nº15-2020- } \\
\text { VIVIENDA - EXPROPIACIÓN) }\end{array}$} \\
\hline Artículo & Acción & Plazo \\
\hline Art 16 & $\begin{array}{l}\text { Identificación del } \\
\text { inmueble }\end{array}$ & - \\
\hline Art 17 & $\begin{array}{c}\text { Elaboración del } \\
\text { expediente técnico }\end{array}$ & 4 meses \\
\hline Art 18 & Emisión de tasación & 30 días hábiles \\
\hline Art 20 & $\begin{array}{l}\text { Carta de intención } \\
\text { de adquisición al } \\
\text { Sujeto Pasivo } \\
\text { (Incluye incentivo } \\
\text { del } 20 \% \text { ) }\end{array}$ & 20 días hábiles \\
\hline Art 20 & No aceptación & 15 días hábiles \\
\hline Art 27 & $\begin{array}{l}\text { Norma que aprueba } \\
\text { la expropiación }\end{array}$ & 15 días hábiles \\
\hline Art 27 & $\begin{array}{l}\text { Notificar al Sujeto } \\
\text { Pasivo para que } \\
\text { realice la entrega } \\
\text { del Inmueble y su } \\
\text { desocupación }\end{array}$ & $\begin{array}{l}\text { Orden de notificar al } \\
\text { Sujeto Pasivo: } \\
\text { a) } 10 \text { días hábiles } \\
\text { para predios libres. } \\
\text { b) } 30 \text { días hábiles } \\
\text { para predios } \\
\text { ocupados. }\end{array}$ \\
\hline Art 31 & Entrega del bien & $\begin{array}{c}\text { Desocupar el } \\
\text { inmueble: } \\
\text { a) } 10 \text { días hábiles } \\
\text { para predios libres. } \\
\text { b) } 30 \text { días hábiles } \\
\text { para predios } \\
\text { ocupados. } \\
\text { c) } 60 \text { días hábiles } \\
\text { para el predio que } \\
\text { necesitan } \\
\text { autorización o } \\
\text { habilitación } \\
\text { administrativa }\end{array}$ \\
\hline & $\begin{array}{l}\text { Total del Plazo } \\
\text { aproximado* }\end{array}$ & 270 días hábiles \\
\hline
\end{tabular}

Fuente: Elaboración propia 
MÉXICO (Ley de expropiación del 25.11.1936, última Reforma DOF 05.06.2009)

\begin{tabular}{|c|c|c|}
\hline Artículo & Acción & Plazo \\
\hline $\begin{array}{l}\text { Artículo } \\
\text { 2o. I }\end{array}$ & $\begin{array}{l}\text { Declaratoria de } \\
\text { Utilidad Pública }\end{array}$ & 0 \\
\hline $\begin{array}{l}\text { Artículo } \\
\text { 2o. III }\end{array}$ & $\begin{array}{c}\text { Presentación de } \\
\text { pruebas o derechos } \\
\text { frente a bien afectado } \\
\text { en la Secretaria de } \\
\text { Estado }\end{array}$ & 15 días hábiles \\
\hline $\begin{array}{l}\text { Artículo } \\
\text { 2o. IV }\end{array}$ & Audiencia de pruebas & 8 días hábiles \\
\hline $\begin{array}{l}\text { Artículo } \\
\text { 2o. IV }\end{array}$ & $\begin{array}{c}\text { Presentación de } \\
\text { alegatos de manera } \\
\text { escrita }\end{array}$ & $\begin{array}{c}3 \text { días } \\
\text { posteriores a la } \\
\text { audiencia } \\
\end{array}$ \\
\hline $\begin{array}{l}\text { Artículo } \\
\text { 2o. VII }\end{array}$ & $\begin{array}{l}\text { Decreto de la } \\
\text { expropiación }\end{array}$ & 30 días hábiles \\
\hline $\begin{array}{l}\text { Artículo } \\
40 .\end{array}$ & Notificación & 15 días hábiles \\
\hline $\begin{array}{c}\text { Artículo } \\
20\end{array}$ & $\begin{array}{c}\text { Pago de } \\
\text { Indemnización } \\
\end{array}$ & 45 días hábiles \\
\hline \multirow[t]{2}{*}{$\begin{array}{c}\text { Artículo } \\
20\end{array}$} & $\begin{array}{c}\text { Pago de } \\
\text { Indemnización }\end{array}$ & 45 días hábiles \\
\hline & Total del plazo * & $\begin{array}{l}161 \text { días } \\
\text { habiles }\end{array}$ \\
\hline
\end{tabular}

* En caso que se interponga el juicio de amparo se interrumpe el plazo de la emisión del decreto de expropiación.

\section{CHILE}

(Decreto Ley 2186 del 09.06.1978, Última versión 02.10.1992)

\begin{tabular}{|c|c|c|}
\hline Artículo & Acción & Plazo \\
\hline Artículo 6 & $\begin{array}{l}\text { Declaración de la } \\
\text { expropiación }\end{array}$ & 0 \\
\hline Artículo 7 & $\begin{array}{l}\text { Publicación de acto de } \\
\text { expropiación }\end{array}$ & 95 días hábiles \\
\hline Artículo 9 & Reclamo ante el juez & 30 días hábiles \\
\hline Artículo 14 & $\begin{array}{l}\text { Exposición de derechos } \\
\text { y designación de peritos }\end{array}$ & 15 días hábiles \\
\hline Artículo 14 & Recepción de pruebas & 8 días hábiles \\
\hline Artículo 14 & Dictado de sentencia & 10 días hábiles \\
\hline Artículo 21 & $\begin{array}{l}\text { Pago de frutos } \\
\text { pendientes }\end{array}$ & 5 días hábiles \\
\hline Artículo 23 & $\begin{array}{l}\text { Presentación de 3eros } \\
\text { interesados }\end{array}$ & 20 días \\
\hline Artículo 26 & $\begin{array}{c}\text { Pago íntegro al } \\
\text { expropiado en caso no se } \\
\text { presenten terceros }\end{array}$ & $\begin{array}{l}\text { vencido el plazo } \\
\text { del artículo } 23\end{array}$ \\
\hline Artículo 27 & $\begin{array}{l}\text { Presentación a audiencia } \\
\text { por parte de terceros } \\
\text { interesados }\end{array}$ & $\begin{array}{c}\text { Plazo } \\
\text { establecido por } \\
\text { el Juez }\end{array}$ \\
\hline \multirow[t]{2}{*}{ Artículo 28} & Dictamen de sentencia & 10 días hábiles \\
\hline & Total del plazo * & $\begin{array}{l}193 \text { días } \\
\text { (aprox.) }\end{array}$ \\
\hline
\end{tabular}

*Este plazo es aproximado debido a que la programación de la "audiencia de terceros interesados" es a discreción del juez.

Fuente: Elaboración propia 


\begin{tabular}{|c|c|c|}
\hline Artículo & Accción & Plazo \\
\hline Artículo 61 & Inicio de Expropiación & 30 días después de la oferta de compra \\
\hline Artículo 62 & Recurso de Reposición & 15 días \\
\hline Artículo 66 & Determinación de expropiación & Sin plazo \\
\hline Artículo 67 & Indemnización y Pago & Con la notificación \\
\hline Artículo 68 & Decisión de la expropiación & 30 días \\
\hline Artículo 69 & Notificación & 10 días hábiles \\
\hline Artículo 70 & Confirmación de pago & 10 días \\
\cline { 2 - 4 } & Total del Plazo* & 95 días hábiles \\
\cline { 2 - 3 } & &
\end{tabular}

* Sin contar procedimientos judiciales.

Fuente: Elaboración propia

Por otro lado, en los últimos años se ha emitido un marco normativo destinado a facilitar el acceso a terrenos estatales para el desarrollo de ciertos proyectos de interés económico relevante a través de la figura del derecho de servidumbre. La norma aplicable es la Ley $\mathrm{N}^{\circ} 3032716$ con la que se buscaba poder proveer a los proyectos públicos y privados de los terrenos estatales necesarios para su desarrollo. Sin embargo, es necesario identificar una serie de "cuellos de botella" que se vienen presentando para su implementación, como son:

a. Falta de determinación de cuándo procede aplicar este procedimiento especial y cuándo procede aplicar otros procedimientos alternativos regulados en las normas de diversos sectores (minería, hidrocarburos, electricidad, telecomunicaciones, etc) La SBN viene promoviendo la interpretación de que en el caso de predios eriazos sólo aplica la servidumbre de la Ley $\mathrm{N}^{\circ} 30327$, considerando una suerte de derogación parcial de los procedimientos sectoriales, esto a pesar de que la propia Ley $\mathrm{N}^{\circ} 30327$ se pronuncia expresamente en sentido contrario.

16 Ley de Promoción de las Inversiones para el Crecimiento Económico y el Desarrollo Sostenible, promulgada el 20 de mayo de 2015. 
b. Interpretaciones restrictivas en cuanto a la posibilidad de usar este mecanismo.

c. Creación de reglamentaciones e interpretaciones que limitan o complican la aplicación de esta alternativa.

d. Los beneficiarios deben esperar a la culminación de las acciones de saneamiento para recibir el derecho definitivo y poder ejercer el uso pleno del bien. Esto debería modificarse y permitir el uso del beneficiario mientras el saneamiento se realiza de forma paralela.

e. Es necesario regular los plazos y alcances de las consultas que se hacen a otras entidades públicas. Se ha podido apreciar que en algunas entidades pueden demorar más de un año para responder y que dan opiniones que no son relevantes para los procedimientos. Esto afecta gravemente a los plazos regulados en la presente normativa, los cuales en principio están diseñados para hacer de este procedimiento mucho más acotado y simplificado.

f. La Ley $\mathrm{N}^{\circ} 30327$ se limita a los predios eriazos de propiedad estatal, consideramos que debería extenderse sus alcances a todos los predios estatales.

g. En el caso de los procedimientos sectoriales para la imposición de servidumbres consideramos necesario mejorar los siguientes aspectos:

i. Agilizar la etapa de valuación de predios.

ii. En los casos de transporte y distribución de hidrocarburos determinar claramente qué áreas deben ser adquiridas y compensadas.

iii. Aclarar que estos procedimientos son alternativos al regulado en la Ley $\mathrm{N}^{\circ} 30327$ y que es potestad del interesado elegir la mejor alternativa, conforme está mencionado en la propia ley $\mathrm{N}^{\circ} 30327$.

iv. Tal como se ha comentado anteriormente, es necesario regular los plazos y alcances de las consultas que se hacen a otras entidades públicas y restringirlas a las estrictamente necesarias.

h. En los procedimientos de adjudicación en propiedad de terrenos estatales.

i. Agilizar la etapa de valuación de predios.

ii. En el caso de ciertos sectores de interés (infraestructura, minería, electricidad, hidrocarburos, etc.) volver a otorgar el derecho a la adjudicación directa.

\section{vi. Propiedad estatal}

Como indicáramos anteriormente, desde nuestro punto de vista, las entidades públicas relacionadas con la administración del derecho de propiedad adolecen de 
una adecuada visión pro ciudadano y pro inversión. Por ello, creemos necesario modificar la visión de la administración de las tierras del Estado priorizando lo siguiente:

a. La administración de las tierras estatales debe enfocarse en su efectivo aprovechamiento y no en su custodia. Las tierras del estado deben cumplir con generar la mayor cantidad de réditos a la sociedad y esto debe entenderse como lograr que sean destinadas al mejor uso posible y que permitan el desarrollo de actividades económicas que a su vez generen empleo e impuestos para la sociedad.

b. La transferencia en propiedad de tierras estatales se debe hacer contra el pago del valor comercial de los bienes. La asignación de los bienes a valor de mercado es el mejor mecanismo para determinar cuál es el uso más valioso del bien y evitar asignaciones arbitrarias. En ese sentido, cuando se ha regulado mecanismos de acceso gratuito o "barato" a la tierra, esto ha sido una puerta abierta para la corrupción y el aprovechamiento.

c. En cualquier caso, también debe garantizarse el acceso a predios estatales para el cumplimiento de fines sociales mediante su asignación a entidades estatales y a organizaciones sin fines de lucro cuyas actividades sean debidamente acreditadas.

d. Por excepción, se debe ceder tierras estatales de manera gratuita en aquellos casos en que las actividades que se buscan desarrollar permitan la generación de inversión relevante (proyecto de interés) y que generen un impacto mayor del de la especulación por el valor de la tierra.

A manera de ejemplo, presentamos el flujograma correspondiente a los procedimientos de venta por subasta pública y venta directa. Como se puede apreciar son procedimientos que normativamente son bastante largos y que en la práctica se hacen aún más largos, afectando el desarrollo oportuno de los proyectos de interés del sector privado. 
Procedimiento de Venta por subasta pública/caso normado (16 meses)

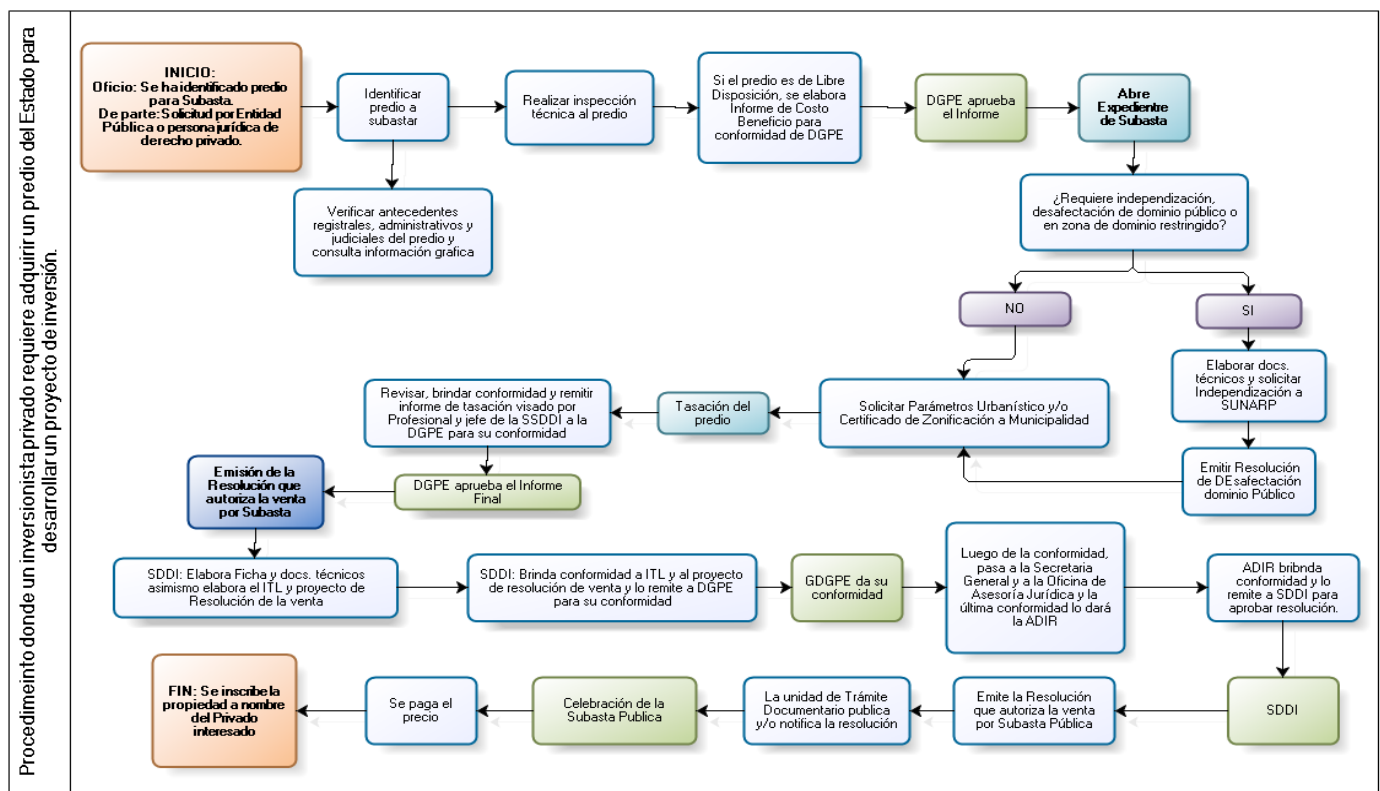

Fuente: Elaboración propia

Procedimiento de Venta por subasta pública/caso real aleatorio (24 meses)

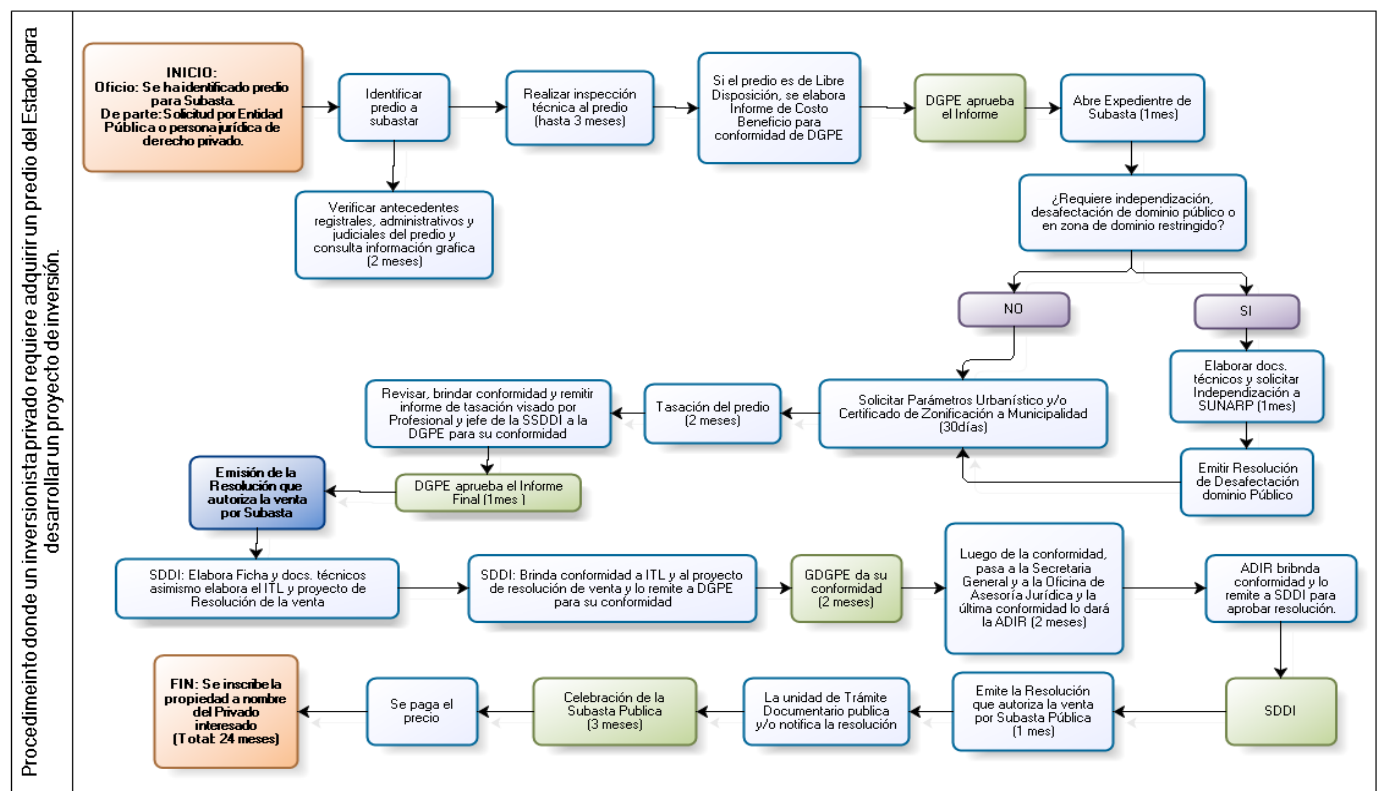

Fuente: Elaboración propia 
Procedimiento de Venta directa/caso normado (18 meses) real aleatorio (32 meses)

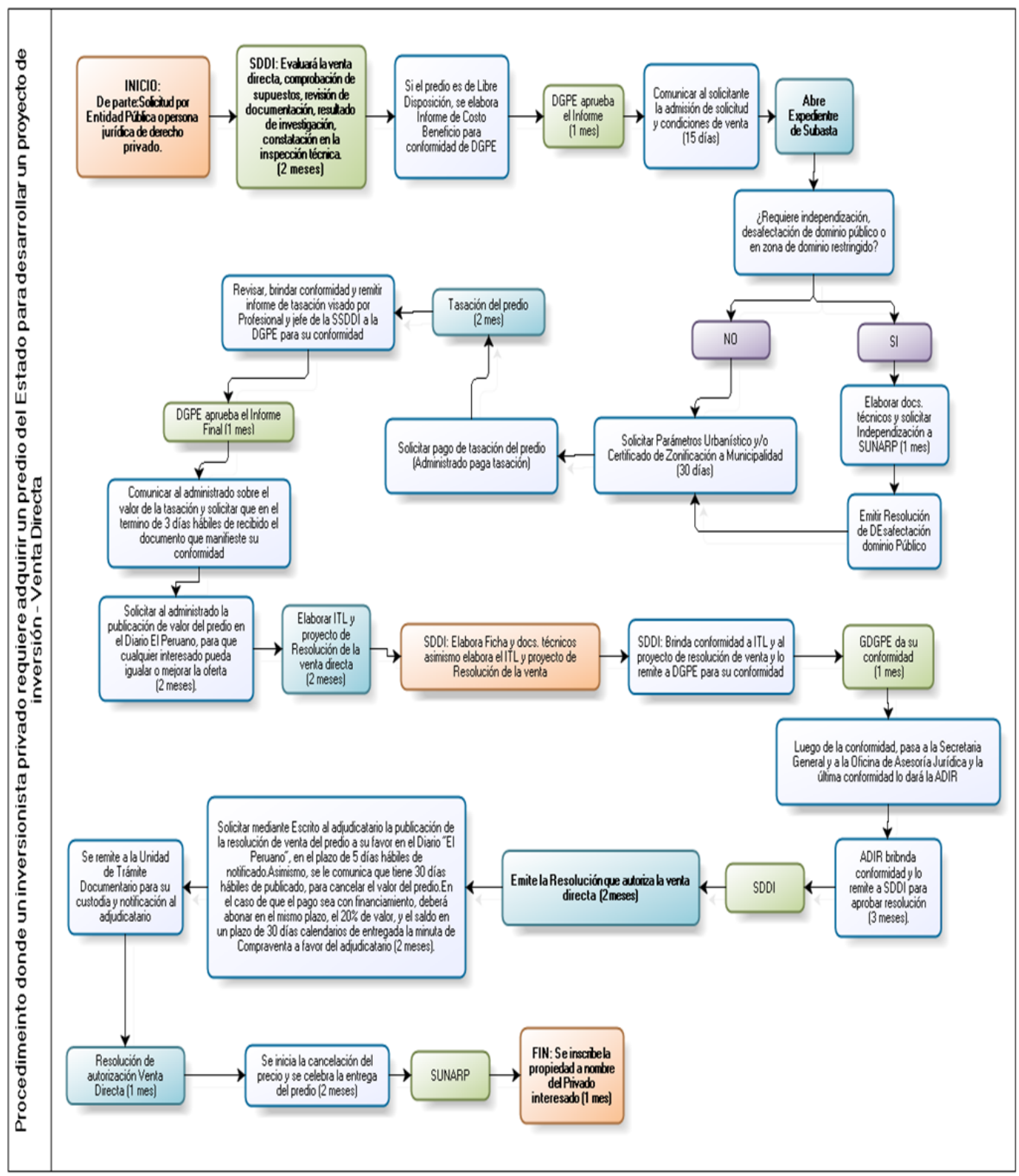

Fuente: Elaboración propia

\section{vii. Propiedad comunal 17}

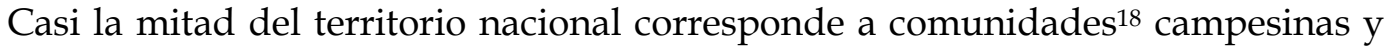
nativas, que coincide con parte importante de los territorios donde se realizan grandes proyectos de inversión, además de actividades agrícolas, ganaderas y forestales. Por ejemplo, de acuerdo con la ONG Cooperacción, alrededor del 38\%

17 RAVINA SÁNCHEZ, Raúl Fernando, Entre lo común y lo privado: El derecho de propiedad de las comunidades campesinas, problemática y propuestas. Lima, Pontificia Universidad Católica, tesis para optar el grado de Magister en Investigación Jurídica, 2021.

18 INSTITUTO DEL BIEN COMÚN, El estado de las comunidades indígenas en el Perú - Informe. Tierras comunales: Más que preservar el pasado es asegurar el futuro. Editorial ISBN, 2016. 
del territorio de las comunidades campesinas cuentan con concesiones mineras adjudicadas.

El régimen de propiedad de las comunidades es un régimen especial que busca proteger la titularidad de las comunidades. En ese sentido, el artículo $89^{\circ}$ de la Constitución declara a las tierras comunales como imprescriptibles y el artículo $7^{\circ}$ de la Ley $\mathrm{N}^{\circ} 24656{ }^{19}$ como inembargables e inalienables. En nuestra opinión, dado que a nivel constitucional solo se mantienen la condición de imprescribitibilidad de las tierras comunales, las mayores limitaciones a la integración de las tierras de las comunidades al mercado están establecidas a nivel legal y, por lo tanto, son de menos compleja implementación. En ese sentido, creemos que es razonable que se mantenga la imprescriptibilidad de las tierras comunales ${ }^{20}$ como un mecanismo de protección frente a la ocupación de terceros y paralelamente flexibilizar los mecanismos para el paso del régimen comunal al de propiedad privada, permitiendo que las comunidades que opten por esta opción puedan implementarlo sin mayores trabas.

El derecho de propiedad comunal debe conjugar la función social y la función económica, en ese sentido, consideramos que deberían evaluarse las siguientes mejoras regulatorias:

a. Proponemos que se dicte una ley que modifique el marco legal vigente y permita regular de manera diferenciada la disposición de las tierras comunales en razón del su uso actual. En ese sentido, se promovería un tratamiento diferenciado para; i) las tierras que vienen siendo explotadas de manera individual/familiar sean tituladas como propiedad privada, ii) las tierras de pastos y de uso público, se mantendrían en titularidad de la comunidad, y, iii) las tierras de secano, también sean tituladas como propiedades privadas. Para ello, la ley permitiría que sean los estatutos de las comunidades los que regulen los casos en que esto procedería y la forma en que se aprobaría, dejando a la ley el establecimiento de quórums y mayorías máximas que reconozcan un nivel de protección mayor para las tierras de pastos y de uso público.

b. Excepcionalmente, proponemos que la ley establezca límites bajos al quórum y a las mayorías máximas para aquellos casos en que la disposición se realiza en favor de los miembros de la comunidad, respecto a los predios que vienen conduciendo de manera exclusiva y permanente, esto con la intención de lograr cierto equilibrio entre el grupo y los comuneros que lo conforman.

19 Ley General de Comunidades Campesinas, promulgada durante la vigencia de la constitución de 1993. En tanto la Constitución de 1993 no mantuvo el carácter inalienable e inembargable de las tierras comunales, somos de la opinión que las limitaciones de la Ley $\mathrm{N}^{\circ} 24656$ han sido derogadas.

20 Condición que comparten con los bienes estatales. 
c. Reconocer el derecho de los pueblos indígenas sobre las tierras que históricamente han ocupado, más allá de contar con títulos de propiedad que acrediten su derecho.

d. Consideramos conveniente que se realice una modificación legal que otorgue expresamente a las asambleas de delegados la facultad de disponer de terrenos comunales, siempre que así lo prevea el estatuto de la comunidad.

e. Proponemos regular específicamente, el derecho de los pueblos indígenas a los recursos naturales que tradicionalmente han venido disfrutando y establecer mecanismos efectivos para otorgarles seguridad jurídica.

f. Proponemos que una entidad centralizada se encargue de la formalización de la propiedad de comunidades campesinas. Los programas masivos de formalización/titulación son procesos que requieren de recursos y conocimientos técnicos especializados, que no necesariamente se encuentran distribuidos de manera proporcional a nivel nacional. Además, se trata de una tarea que tiene carácter temporal, al menos en su etapa masiva y que, por lo tanto, no se justifica una competencia permanente de los gobiernos regionales.

g. A nuestro entender, no basta con que, como sucede actualmente, el gobierno central asuma una función rectora de la formalización de la propiedad a cargo de los gobiernos regionales, pues este modelo no ha mostrado funcionar adecuadamente.

h. Proponemos fortalecer los mecanismos destinados a garantizar los derechos de las comunidades, como el deslinde y titulación y procedimientos eficaces para la resolución de conflictos sobre sus tierras, pues constituyen instrumentos necesarios para garantizar estos derechos.

i. Debería reconocerse expresamente la posibilidad que un caserío o anexo comunal se independice de una comunidad y que la mayoría calificada que se exige sea menor a la requerida para actos de disposición en favor de personas ajenas a la comunidad.

j. Se debe realizar un proceso especial para la georreferenciación de las tierras de las comunidades campesinas ya tituladas. Para ello, deberá generarse un marco legal especial para resolver los problemas de superposición que la falta de georreferenciación ha generado.

k. Establecer a nivel administrativo y normativo criterios claros para dilucidar disputas de límites respecto a predios comunales y capacitar al Poder Judicial en esta temática especial.

1. Hacer efectivo el uso de la conciliación y el arbitraje, como mecanismos alternativos de la Ley de Deslinde y Titulación de Comunidades 
Campesinas, para que se resuelvan las disputas en relación con los linderos comunales.

m. Regular un procedimiento judicial especial, para resolver los problemas de deslinde de las comunidades, con plazos recortados y jueces especializados.

Establecer lineamientos respecto a qué tipo de título es el adecuado para alegar un derecho de propiedad que pueda oponerse a la pretensión de una comunidad campesina, por ser anterior a 1920.

\section{Debate electoral y derecho de propiedad}

En el momento de escribir este artículo están por definirse los resultados de las elecciones presidenciales para el periodo 2021-2026, que en segunda vuelta enfrentan al señor Pedro Castillo Terrones, candidato del partido político Perú Libre y a la señora Keiko Fujimori Higushi.

El debate electoral en la segunda vuelta ha estado marcado por los cuestionamientos al modelo económico establecido en la Constitución de 1993 y por el planteamiento de una reforma integral de la constitución a través de una asamblea constituyente. En ese sentido, ha sido el candidato Pedro Castillo quien se ha mostrado más critico del sistema económico vigente que tiene al sistema de derechos de propiedad que hemos descrito como una de sus piedras angulares.

No es del todo claro que medidas especificas podrían ser tomadas en materia de derechos de propiedad en caso se decida implementar un cambio significativo del régimen actual vigente, sin embargo, podemos comentar algunos aspectos sobre los que se podrían considerar cambios de importancia.

En primer lugar, creemos que es importante que se mantenga la existencia de los tres regímenes de derechos de propiedad pues cada uno de ellos regula bienes sujetos a situaciones distintas. En ese sentido, es un error creer que el régimen de propiedad privada es superior a la propiedad comunal o estatal, así como es un error que la propiedad comunal o la propiedad estatal son siempre mejores instrumentos que la propiedad privada. Cada sistema responde a necesidades y objetivos distintos y deberíamos mantener ese abanico de alternativas en nuestra sociedad.

En segundo lugar, nuestra Constitución actual fortaleció la protección de los derechos de propiedad declarándolos inviolables, salvo en casos de seguridad nacional y necesidad pública, en que, con autorización de ley y previo pago de una indemnización justa, se puede expropiar un bien particular. Este tratamiento es la piedra angular de la protección de la propiedad privada frente a potenciales abusos del Estado que, hasta antes de su implementación, admitía que el Poder Ejecutivo afecte la propiedad privada en mayor cantidad de casos (utilidad pública), sin necesitar la autorización del congreso ni compensar económicamente a los afectados. 
En tercer lugar, nuestra constitución hace referencia a la figura del abandono de tierras agrarias de propiedad privada y comunal como causal de perdida del derecho de propiedad en favor del Estado. Si bien este es un mecanismo de despojo del derecho de propiedad adicional a la expropiación, hay que indicar que en la práctica este no viene operando por falta de regulación. En nuestra opinión, este mecanismo de afectación al derecho de propiedad es un rezago de épocas anteriores en que privar del derecho de propiedad a los ciudadanos sin compensarlos, era una práctica aceptada. Por lo tanto, la reimplementación de este mecanismo podría generar un debilitamiento de los derechos de propiedad en el Perú.

Finalmente, en materia de propiedad comunal nuestra constitución ha restringido sus limitaciones a la imprescriptibilidad de sus tierras, dejando a la ley el mantenimiento de las condiciones de inalienabilidad e inembargabilidad que aún se mantienen vigentes. En ese sentido, es posible que se plantee un endurecimiento se estas limitaciones so pretexto de brindar mayor protección a las comunidades, pero sin tener en cuenta que estas restricciones implican limitaciones a su desarrollo económico. En nuestra opinión, si bien puede justificarse algún nivel de protección de las comunidades, es preferible que estas puedan decidir cuándo acogerse a esta protección y cuando optar por integrarse al mercado, en ese sentido, la regulación no debe ser tan rígida y debe permitir que las comunidades tomen sus propias decisiones.

\section{Conclusión}

Como adelantamos en la introducción de este artículo, en el Perú, es necesario enfrentar la falta de una visión integral de los derechos de propiedad e implementar mejoras a nivel normativo e institucional que permitan facilitar nuestro desarrollo de cara al bicentenario. No obstante ello, este proceso requiere un manejo técnico del tema y que no se promuevan cambios que terminen debilitando la protección de los derechos de propiedad en el país. 